\title{
Implementasi Nilai Pendidikan Islami melalui Filosofi Gusjigang bagi Masyarakat Kudus Kulon Septy Nadia Salma ${ }^{1, a^{*}}$
}

${ }^{1}$ Institut Agama Islam Negeri, Kudus, Kabupaten Kudus, Indonesia

Email: septynadiasalma52@ gmail.com ${ }^{\mathrm{a}}$

\begin{abstract}
:
The purpose of this research is to find out how to implement Islamic educational values in Gusjigang philosophy in Kudus Kulon. Gusjigang's philosophy has noble values that have been taught and applied by the people of Kudus Kulon. So the cultivation of Gusjigang Islamic educational values can be continued by today's young generation to be used as guidelines for daily activities. This type of research is a phenomenological research with a qualitative approach. Data collection techniques through interviews. Then analyzed into meaningful information for the reader. The setting of this research was carried out in the Kudus Tower community area. The subjects of this research are the people of Kudus Kulon, the manager of the Gusjigang Kudus store, and the shops around the Kudus tower. The results of this study indicate the values of Islamic education contained in Gusjigang, namely there are 6 values philosophical, moral, scientific, spiritual, artistic, and economic. The implications of Gusjigang have a positive impact on society. The implications are Good: good manners, good morals in carrying out daily activities, Ngaji: knowledgeable, and able to practice it to others, Trade: diligent in trading, trade and worship run in a balanced way.
\end{abstract}

Keywords: Gusjigang Philosophy, Value, Islamic Education, Gusjigang

\begin{abstract}
Abstrak:
Tujuan penelitian ini untuk mengetahui implementasi nilai-nilai pendidikan Islami dalam filosofi Gusjigang di Kudus kulon. Filosofi Gusjigang mempunyai nilai yang berakhlak mulia yang telah diajarkan dan diterapkan oleh masyarakat. Maka penanaman nilai-nilai pendidikan Islam Gusjigang dapat diteruskan oleh generasi muda sekarang ini untuk dijadikan pedoman aktivitas sehari-hari. Jenis penelitian ini merupakan penelitian fenomenologi dengan pendekatan kualitatif. Teknik pengumpupan data melalui wawancara. Kemudian dianalisa menjadi informasi yang berarti bagi si pembaca. Setting penenlitian ini dilakukan di kawasan masyarakat menara Kudus. Subjek dari penelitian ini masyarakat Kudus Kulon, pengelola toko Gusjigang Kudus, dan toko sekitar menara Kudus . Hasil penelitian ini menunjukkan bahwa nilai-nilai pendidikan Islam yang terdapat dalam Gusjigang ada 6 nilai: filosofis, akhlak, ilmiah, spiritual, karya, dan ekonomi. Implikasi Gusjigang berdampak positif terhadap masyarkat yaitu bagus: sopan santun, berakhlakul karimah dalam melakukan kegiatan sehari-hari, ngaji: berilmu, dan mampu mengamalkannya kepada sesama, dagang: rajin dan tekun dalam berdagang, antara berdagang dan beribadah menjalankannya secara seimbang.
\end{abstract}

Kata Kunci: Filosofi Gusjigang, Nilai, Pendidikan Islam Kehidupan, Gusjigang

Cara mensitasi artikel ini:

Salma, S. N. (2022). Implementasi nilai pendidikan islami melalui filosofi Gusjigang bagi masyarakat Kudus Kulon. Mitra PGMI: Jurnal Kependidikan MI, 8(1), 50-59. https://doi.org/10.46963/mpgmi.v8i1.442

\section{Informasi Artikel}

*Corresponding author:

septynadiasalma52@gmail.com

DOI:

https://doi.org/10.46963/mpgmi.v8i1.442
Histori Artikel:

Diterima :09/12/2021

Direvisi : : 19/01/2022

Diterbitkan : 31 / $01 / 2022$ 
Septy Nadia Salma

Implementasi Nilai Pendidikan Islam melalui Filosofi Gusjigang Bagi Masyarakat

Kudus Kulon

\section{PENDAHULUAN}

Bangsa Indonesia merupakan bangsa yang besar, mempunyai wilayah yang luas sekali, sehingga mempunyai beraneka ragam budaya lokal yang mempunyai kearifan, bahkan dijadikan sebagai norma-norma oleh masyarakat. Untuk itu perlunya penanaman nilai-nilai pendidikan agama untuk mewariskan kepada generasi selanjutnya. Akan tetapi melihat keadaan yang ada di lapangan. Makin menurunnya karakter (akhlak) yang menyebabkan banyak terjadi kenalan remaja, tawuran dan juga tidak melestarikan kebudayaan atau tradisi daerah sendiri

Kenakalan remaja muncul akibat hilang nya nilai-nilai luhur yang diajarkan oleh bangsa ini pada masanya, seperti leluhur Sunan Kudus yaitu Ja'far Shadiq yang merupakan salah satu tokoh Walisanga di tanah Jawa. Perpaduan unsur Islam dengan unsur lokal yang dilakukan Raden Ja'far Shadiq tampak pula pada cerita legenda yang mengaitkan tokoh Sunan Kudus dengan pelarangan masyarakat, khususnya masyarakat Kudus untuk tidak menyembelih dan tidak memakan daging sapi yang pada saat itu dianggap sebagai hewan yang dimuliakan dan dihormati orang-orang beragama Hindu.

Pada zaman pengembangan Islam dahulu Sunan Kudus menata kembali kota Kudus. Kota tersebut berpusat di Masjid Al-Aqsha dan Menara Kudus yang berdekatan dengan pusat pengajaran ilmu agama, di sekeliling Sunan Kudus juga terdapat rumah warga. Sunan Kudus mulai mengajarkan kepada murid muridnya dan masyarakat Kudus sekitarnya agar berbudi pekerti yang bagus, rajin atau pandai mengaji dan berdagang. Ajaran ini betul-betul dianut oleh masyarakat pada kala itu, sehingga banyak yang sukses menjadi saudagar. Kesuksesan tersebut menyebabkan mereka berlomba lomba membangun rumah yang bertembok tinggi. Hingga saat ini kawasan tersebut dikenal dengan kawasan elite Kudus Kulon. Gusjigang itu sebenarnya tidak hanya berupa falsafah hidup tetapi juga sebagai suatu kebudayaan dan juga sebagai sebuah pendidikan karakter yang telah lama diterapkan kepada masyarakat Kudus (Esha, 2015).

Makna dari Gusjigang yaitu bagus, ngaji dan dagang dan merupakan sebuah filosofi yang diajarkan oleh Sunan Kudus untuk masyarakat Kudus dan sekitarnya. Filosofi Gusjigang sangat melekat bagi masyarakat Kudus karena dianggap sebagai bentuk untuk mewujudkan karakter yang baik bagi masyarakat Kudus sehingga memiliki nilai-nilai pendidikan Islami. Selama ini masyarakat Kudus dikenal sebagai seseorang yang bagus dalam penampilan, mempunyai jiwa yang baik perilakunya dan mempunyai pemahaman agama yang luas. Gusjigang di Kudus juga menciptakan core value yang berpotensi dalam bidang ekonomi melalui dagang, politik, seni, budaya, maupun pendidikan. Maka dengan adanya Gusjigang di Kudus perlu adanya penanaman nilai-nilai pendidikan Islami bagi masyarakat

51 Print - ISSN: 2443-0021

Online - ISSN: 2716-4136 
Kudus untuk diwariskan ke generasi selanjutnya agar dimasa sekarang ini generasi muda sekarang bisa mengurangi perilaku tercela seperti menurunya karakter (akhlak) sehingga terjadi kenakalan remaja seperti sekarang ini (Abid, 2018).

Kepandaian Sunan Kudus dalam berdakwah dapat dilihat dari latar belakang beliau sebagai pedagang dan sebagai wali yang mempunyai kapasitas penguasaan ilmu agama yang sangat mumpuni. Maka tidak heran Sunan Kudus dijuluki Wali Saudagar karena keahlian beliau berdagang dan mempunyai etos kerja yang sangat tinggi. Beliau juga dijuluki waliyyul ilmi karena menguasai keilmuan islam maupun ilmu-ilmu lainnya (Nawali, 2018).

Sunan Kudus berdakwah dengan menggunakan metode hilang hal, karena dengan metode tersebut membuat agama Hindu tertarik untuk memperdalam dan memeluk agama Islam. Sunan Kudus juga berperan penting untuk menyadarkan masyarakat Kudus dalam berperilaku dan bertutur kata yang sopan. Beliau juga pandai berdagang sehingga ia melakukan dakwahnya dengan berdagang. Maka tidak heran Sunan Kudus dijuluki Wali Saudagar karena keahlian beliau berdagang dan mempunyai etos kerja yang sangat tinggi. Beliau juga dijuluki waliyyul ilmi karena menguasai keilmuan islam maupun ilmu-ilmu lainnya. Julukan Sunan Kudus sebagai wali saudagar dan juga waliyyulilmi sangat melekat dalam kehidupannya. Hingga saat ini makam Sunan Kudus dan museum Gusjigang masih dikunjungi masyarakat Kudus dan sekitarnya. Hal ini terbukti bahwa Sunan Kudus mempunyai filosofi hidup yang sudah terkenal di kalangan masyarakat Kudus, yaitu Gus-Ji-Gang, yang bisa dilihat sebagai salah satu jenis budaya yang mempunyai kearifan lokal, yang telah menjadi pedoman hidup masyarakat Kudus dan sekitarnya (Abid, 2018).

Gusjigang merupakan karakter yang harus dimiliki masyarakat Kudus Kulon. Gusjigang singkatan dari Bagus akhlaknya, pintar mengaji, dan trampil berdagangketiga karakter inilah yang menjadi filosofi hidup Sunan Kudus untuk diterapkan di masyarakat yang dapat dijelaskan sebagai berikut :

Gus yang berarti Bagus, yang secara istilah diartikan baik (bagus) akhlaknya, berakhlakul karimah. Manusia harus menerapkan konsep ini, karena sangat penting bagi kehidupan manusia. Selain melaksanakan perintah ibadah dalam Islam tentunya dibarengi dengan perilaku yang bagus, sehingga akan mencetak generasi berakhlak/berkarakter. Ji yang mempunyai banyak penafsiran dikalangan masyarakat Kudus, ada yang mengartikan Ngaji (menuntut Ilmu), yang pada intinya menyuruh masyarakat agar menuntut ilmu (ngaji) atau membagikan ilmunya (mengajar) dan selalu menghormati orang lain. Dan Gang yang mempunyai arti berdagang, dengan adanya filosofi Gusjigang mayoritas masyarakat Kudus menjadi pembisnis atau wirausaha. Maka dari itu, penulis ingin mengetahui mengenai apa saja nilai-nilai pendidikan Islami dan implementasi yang terkandung dalam filosofi 
Septy Nadia Salma

Implementasi Nilai Pendidikan Islam melalui Filosofi Gusjigang Bagi Masyarakat

Kudus Kulon

Gusjigang sebagai pedoman hidup yang ada di masyarakat Kudus Kulon dan sekitarnya dalam mengimplementasikan kehidupan sehari-hari.

\section{METODE PENELITIAN}

Jenis penelitian ini merupakan penelitian fenomenologi dengan pendekatan kualitatif. Pendekatakan ini menggambarkan keadaan objek yang diteliti berdasarkan fakta yang ada, kemudian dianalisa menjadi informasi yang berarti bagi si pembaca. Setting penenlitian ini dilakukan di kawasan masyarakat menara Kudus Kulon. Subjek dari penelitian ini masyarakat Kudus Kulon, pengelola toko Gusjigang Kudus, dan toko sekitar menara Kudus. Data yang terkumpul di organisir sesuai dengan masalah yang akan dibahas kemudian dianalisa dan membandingkan data dari subjek beberapa orang, kemudian di interpretasikan dan diberi kesimpulan.

\section{HASIL DAN PEMBAHASAN}

\section{Nilai-Nilai Pendidikan Islam dalam Gusjigang}

Nilai pendidikan Islam harus dimiliki tiap individu seseorang agar mengarahkan kepada ajaran yang baik dan benar. Maka nilai-nilai pendidikan Gusjigang tercantum ada 6, yaitu Nilai Filosofi, Nilai Akhlak, Nilai Ilmiah, Nilai Spiritual, Nilai karya, dan Nilai Ekonomi. Nilai filosofi dalam kehidupan manusia tidak akan berjalan baik tanpa adanya nilai-nilai kebaikan yang tertinggal dalam diri individu manusia, dengan mempunyai nilai yang baik manusia akan menjalankan norma-norma yang ada di masyarakat.

Gusjigang jika ditinjau dari nilai filosofi yang telah lama menjadi pedoman bagi kehidupan masyarakat kudus dan sekitarnya dalam mengaplikasikan nilai-nilai pendidikan Islam yang terkandung di dalamnya, karena di dalam Gusjigang menuntut seseorang untuk mengaji dan mempelajari atau mengamalkan nilai-nilai pendidikan Islami. Orang yang paham tentang konsep Gusjigang ia akan mempraktikkan nilai-nilai yang ada di dalam Gusjigang dalam kehidupan seharihari. Seperti masyarakat Kudus yang berdagang di sekitar Menara Kudus ketika melakukan wawancara " Pedagang di sekitar Menara Kudus ketika berjualan ia menerapkan nilai Filosofi Gusjigang yaitu berdagang dengan jujur, karena di lingkungan sekitar Menara Kudus sangat didukung dengan religiositas nya karena salah satu nilai filosofi yaitu jujur, berarti para pedagang telah menegakkan nilai kebenaran dan keadilan dalam berdagang ". Jadi nilai-nilai filosofis merupakan salah satu nilai dalam pendidikan Islam Gusjigang yang ada di Kudus Kulon dan telah dilaksanakan oleh sebagian besar warganya. seperti dalam perdagangan merupakan mata pencaharian mereka. Mereka melaksanakannya dengan kejujuran, mereka sendirilah yang akan menanggung kehilangan kepercayaan dari orang lain

53 Print - ISSN: 2443-0021

Online - ISSN: 2716-4136 
karena tidak berbuat jujur dalam berdagang. Dan juga dalam masyarakat, menyadari dan melaksanakan perintah Allah SWT. Oleh karena itu banyak nilainilai filosofis yang terdapat di dalamnya merupakan bentuk ajaran agama Islam yang diperintahkan oleh Allah SWT. Yang sudah membudaya di masyarakat Kudus Kulon karena setiap manusia dapat merasakan manfaatnya (Ihsan, 2018).

Akhlak dalam kehidupan manusia sangat penting untuk membentuk perilaku dengan perbuatan yang baik, begitu pula dengan nilai-nilai akhlak yang terdapat di filosofi Gusjigang. QS Al-Qalam (68) :4 yang artinya " Dan sesungguhnya kamu benar-benar berbudi pekerti yang agung". Potongan ayat tersebut dapat disimpulkan bahwa akhlak merupakan perbuatan mulia yang juga di contohkan oleh nabi Muhammad, karena nabi Muhammad adalah utusan untuk menyempurnakan akhlak manusia. Oleh karenanya banyak yang menyebut akhlak Islam atau akhlak islami. Karena pada dasarnya akhlak berlandaskan pada Al Quran dan Sunnah yang digunakan umat Islam sebagai sumber hukum Islam. Seperti wawancara yang saya lakukan dengan Bapak Arifin pedagang kaki lima di sekitar menara Kudus ia mengatakan bahwa orang-orang yang berada di lingkungan Menara Kudus mempunyai akhlak yang baik, misalnya kegiatan yang dilakukan positif, murah senyum, dan dilingkungan tersebut banyak Pesantren sehingga tidak ada yang bertingkah macam-macam seperti berbuat kejahatan. Sementara itu Bapak Nor pemilik toko Baju Muslim mengatakan bahwa masyarakat Kudus Kulon menerapkan nilai akhlak dengan cara sopan santun, saling menghormati kepada yang lebih tua, misalnya berjalan dengan kepala menunduk atau melemparkan senyuman terlebih dahulu. Jadi nilai-nilai akhlak merupakan salah satu nilai pendidikan Islam Gusjigang yang diterapkan oleh masyarakat Kudus kulon (Maharromiyati, 2016).

Ilmu dalam Islam merupakan bagian yang sangat penting, maka dari itu manusia dituntun untuk selalu menuntut ilmu baik ilmu agama maupun ilmu umum agar manusia mempunyai pengetahuan mengenai kedua ilmu tersebut serta berbagai macam-macam ilmu lainnya. Masyarakat kudus, khususnya Kudus Kulon menyekolahkan anaknya ke sekolah yang terdapat 2 ilmu yaitu duniawi dan Ukhrowi, misalnya di sekolah Qudsiyah, TBS, Banat, dan sekitarnya yang berbasis Islami. Tujuan nya agar anak dapat memahami kedua ilmu tersebut dan dapat diterapkan dalam kehidupannya sehingga menjadi pribadi yang bermanfaat bagi sekitarnya. Mempunyai ilmu yang banyak maka akan memperoleh wawasan dan pemikiran yang luas. Bentuk nyata mengamalkan ilmu adalah mempunyai perilaku yang baik (nilai bagus) yang diterapkan dalam masyarakat luas.

Nilai Spiritual juga terdapat dalam Nilai Gusjigang, karena dalam nilai tersebut mengandung setiap tingkah laku seseorang yang berpedoman pada Alquran dan As sunnah dengan tujuan berperilaku sesuai ajarannya. Nilai spiritual pasti 
Septy Nadia Salma

Implementasi Nilai Pendidikan Islam melalui Filosofi Gusjigang Bagi Masyarakat

Kudus Kulon

dijalankan dalam kehidupan sehari-hari oleh manusia sebagai sikap menaati perintah Allah SWT, seperti menjalankan rukun Islam. Karena tujuan hidup manusia diciptakan oleh Allah SWT untuk menyembah Allah SWT dan menjauhi larangan nya. Dalam kehidupan masyarakat Kudus Kulon menerapkan nilai spiritual dengan mengadakan rutinan berjanjen, tahlilan, yasinan setiap malam Jumat yang di ikuti oleh anak-anak sampai dewasa.

Nilai karya yang terdapat di Gusjigang yaitu konsep berdagang yang di dalam terdapat nilai karya, karena di zaman modern ini manusia dituntun untuk selalu kreatif dan inovatif mengikuti perkembangan zaman, misalnya di toko pusat oleholeh Gusjigang Kudus terdapat pajangan suatu karya seni yang hingga kini menjadi edukasi bagi pelajar Kudus dan sekitarnya. Hasil karya seni tersebut dihasilkan oleh seniman Kudus dan sekitarnya yang saat ini dijadikan pelajar Kudus dan sekitarnya untuk mempelajari filosofi sepertinya karya seni dimensinya hingga dijadikan sebuah referensi pembelajaran tugas yang diberikan oleh gurunya. Selain itu pemuda pemudi Kudus Kulon menciptakan kreasi melalui barang bekas atau berkreasi sesuai keahliannya (melukis, menggambar, dll). kegiatan tersebut adalah upaya pemerintah desa dan masyarakat untuk membuat kegiatan rutinan, khususnya dalam rangka meminimalisir kenakalan remaja dengan cara memperbaiki akhlak yang kurang baik, dan memberikan wadah serta ajang menyalurkan bakat dan minat pada umumnya.

Nilai karya pedagang bisa di praktikkan dalam berbagai macam hal namun harus di sesuaikan dengan profesinya sebagai pedagang tertentu. Jadi nilai-nilai karya merupakan salah satu nilai dalam pendidikan Islam Gujigang yang ada di Desa Kudus Kulon terutama bagi masyarakat yang berprofesi sebagai pedagang. Masyarakat pedagang mempunyai kreativitas, ulet, dan selalu mempunyai inovasi yang baru untuk menarik minat pembeli.

Islam memperbolehkan cara mendapatkan harta yang sesuai dengan syariat agama Islam, dalam hal ini ada beberapa cara untuk mendapatkan harta, diantaranya adalah ; bercocok tanam di sawah atau pertanian, bekerja atau berdagang. Dari ketiga macam cara mendapatkan harta yang dianjurkan Islam. Ajaran Gusjigang termasuk ada didalamnya yaitu berdagang yaitu suatu akad perpindahan hak milik seperti jual-beli. Dalam praktiknya seorang muslim selain berperilaku baik, rajin ngaji, dan juga di anjurkan untuk berdagang, sebagai bentuk mencari rezeki.

Nilai pendidikan islami Gusjigang salah satunya nilai ekonomi yang terdapat para pedagang kaki lima, pengusaha toko baju muslim, pengusaha toko jenang, dan sejenisnya. Islam memandang ekonomi hal yang sangat penting, karena jika perekonomian daerah maju maka pertumbuhan dan perkembangan ekonomi daerah tersebut maju. Dari hasil wawancara dengan Bapak Wilmy yang berprofesi sebagai 
pedagang busana muslim, beliau mengatakan "jaman dahulu sampai sekarang, memang profesi yang dikerjakan di sekitar Menara Kudus itu Gusjigang (berdagang), dan orang-orang sekitar Kudus, seperti Jepara, Demak, Pati, itu juga mengikuti atau mengakui kalau orang-orang Kudus itu pinter dalam berdagang, dan mereka juga banyak yang kulakan di Kudus. Entah kulakan dari segi barangnya, atau pemikirannya, atau keilmuannya. Yang saya ketahui seperti itu." Jadi nilainilai ekonomi/harta merupakan salah satu nilai dalam pendidikan Islam Gusjigang yang ada di Kudus Kulon terutama bagi masyarakat yang berprofesi sebagai pedagang. Harta merupakan hal yang sangat penting dalam menyambung hidup untuk memperoleh kemakmuran. Dengan berdagang maka masyarakat akan makmur dan tidak menggantungkan nasibnya kepada orang lain, artinya dengan berdagang masyarakat bisa hidup mandiri tanpa ketergantungan orang lain.

\section{Implikasi Gusjigang terhadap Kehidupan Masyarakat}

Implikasi nilai pendidikan Islam Gusjigang yang dirasakan bagi kehidupan masyarakat Kudus Kulon yaitu berdampak positif bagi kehidupannya, maka sampai saat ini masih digunakan oleh masyarakat Kudus Kulon. Implikasi yang diterapkan dari Gusjigang yaitu bagusnya(akhlaknya), ngajinya (spiritual), dan berdagang (Ekonomi).

Tujuan dari mengimplementasikan bagus(akhlaknya) adalah menghasilkan sesuatu yang baik dari proses penerapan nilai Gusjigang bagi masyarakat Kudus Kulon. Dalam proses mengimplementasikan nilai tersebut masyarakat Kudus Kulon mengadakan kegiatan yang berlandaskan sesuai syariat Islam seperti IPNU, IPPNU, Fatayat, PKK, dll. Karena dengan adanya kegiatan tersebut dapat mempererat tali silaturahmi serta dapat bersosialisasi dengan orang lain. Selain itu ada kegiatan keislaman yang masih eksis seperti tadarus Al-Quran, berjanjen, ngaji kitab, manaqiban, tahlilan, yasinan dan lain-lain. Pada intinya semua kegiatankegiatan yang berada di Kudus Kulon mengandung unsur keislaman di dalamnya karena selalu di awali dengan tahlil. Kegiatan-kegiatan tersebut merupakan bentuk pengalaman dari ngaji (menuntut ilmu) yang dipraktikkan dalam kehidupan seharihari (Said, 2016).

Implikasi ngaji yang ada di dalam nilai Gusjigang bertujuan mengajak manusia untuk selalu belajar dan menuntut ilmu kapan pun dan di mana pun berada tanpa memandang usia. Karena ngaji dan menuntut ilmu wajib hukumnya bagi setiap muslim seperti hadist tersebut Uthlubul 'ilma minal mahdi ilal lakhdi. Artinya: "Tuntutlah ilmu dari buaian (bayi) hingga liang lahat." "Menuntut ilmu adalah kewajiban bagi setiap individu muslim."

Perilaku yang diterapkan masyarakat tersebut adalah teori dari ilmu-ilmu yang didapatkan saat ngaji, yang nantinya akan diwujudkan dalam bentuk perilaku 
Septy Nadia Salma

Implementasi Nilai Pendidikan Islam melalui Filosofi Gusjigang Bagi Masyarakat

Kudus Kulon

kebiasaan dalam kehidupan sehari-hari. Sehingga masyarakat Kauman mempunyai akhlakul karimah sesuai dengan ajaran Sunan Kudus yang pertama yaitu Bagus.

Masyarakat Kudus Kulon mengimplementasikan ngaji melalui cara bersekolah islami, mondok, dan mengikuti ngaji di mushola atau masjid sekitarnya. Hasil dari proses penerapan tersebut adalah terbentuknya masyarakat yang memiliki wawasan ilmu agama dan ilmu umum.

Dalam implikasi ngaji di Kudus Kulon bisa dilihat dari pola kehidupan masyarakatnya, yaitu tingkah laku masyarakat yang sopan santun, berpakaian celana bahkan bersarung bagi laki-laki dan selalu berjilbab bagi perempuan dewasa, masyarakat dapat bersosialisasi karena sering bertemu dalam satu majelis, dengan berilmu masyarakat juga dapat membuka wawasan dalam berpikir (Ihsan, 2018).

Syekh Ja'far Shodiq Sunan Kudus dan Nabi Muhammad SAW sama sama berdagang, masing-masing dari beliau juga mempunyai filosofi hidup. Salah satu filosofi hidup yang diajarkan Nabi SAW. Adalah "Dunia itu sawah-ladangnya akhirat" (al-dunya mazra'at al-akhirah) dan pentingnya menjaga keseimbangan hidup. Berangkat dari filosofi ini, potongan hadits tersebut sebenarnya mengungkapkan bahwa segala sesuatu yang telah dianugerahkan Tuhan kepada manusia dalam kehidupan merupakan modal untuk menggapai kebahagiaan akhirat. Maka salam melaksanakan perdagangan diperbolehkan, karena dengan berdagang tidak berorientasi kepada dunia saja tetapi berorientasi pada akhirat (dalam hal berdagang dengan jujur) .

Perilaku masyarakat Kudus Kulon yang menerapkan usaha perdagangan tentu sesuai dengan QS. Al-Qashas [28] : 77. Kekayaan, jabatan, popularitas dan sebagainya adalah wujud anugerah Tuhan yang perlu difungsikan sebagai bekal/modal menggapai akhirat. Penggalan ayat berikutnya yang menyebutkan dan janganlah kamu lupa bagian/keberuntunganmu dari dunia. Oleh karena itu dalam melaksanakan perdagangan itu diperbolehkan, karena dengan berdagang bukan hanya berorientasi kepada dunia saja, tetapi juga berorientasi kepada ukhrowi (Djoko, 2016).

Implikasi perdagangan bagi kehidupan masyarakat Kudus Kulon adalah mengajarkan setiap manusia untuk selalu berusaha dengan berdagang. Setiap usaha yang dijalankan tak hanya bermodalkan ulet dan kerja keras, tetapi juga melibatkan agama, yaitu melaksanakan seluruh perintah agama. Yang perlu diperhatikan adalah dalam implementasinya antara usaha dan ibadah harus dilaksanakan secara seimbang dan proporsional, artinya ada keseimbangan antara dunia dan akhirat, jasmani dan rohani atau sains dan agama (Nur, 2013). 


\section{KESIMPULAN DAN SARAN}

Berdasarkan penelitian di atas membahas implementasi nilai pendidikan Islam melalui filosofi Gusjigang bagi masyarakat Kudus Kulon. Dalam penelitian ini dapat mengetahui bagaimana masyarakat Kudus Kulon mengimplementasikan nilai-nilai filosofi Gusjigang dalam kehidupannya. Semua filosofi gusjigang sangat berkaitan erat dengan kehidupan sehari-hari, dan juga melibatkan ajaran agama Islam didalamnya. Di dalam filosofi ini menerapkan keseimbangan dunia dan akhirat, tidak hanya melibatkan urusan dunia saja melainkan urusan akhirat juga. Filosofi gusjigang harus tetap diteruskan dan diterapkan oleh seluruh masyarakat Kudus Kulon dan sekitarnya. Terutama oleh generasi muda era sekarang ini agar tidak terpengaruh akibat kenakalan remaja dan arus globalisasi dunia, karena di dalam filosofi ini mempunyai nilai-nilai luhur islami yang sangat bermanfaat.

Masyarakat Kudus Kulon mengimplementasikan nilai-nilai pendidikan Islam yang terdapat dalam filosofi Gusjigang yaitu ada 6 nilai: filosofis, akhlak, ilmiah, spiritual, karya, dan ekonomi. Nilai filosofi diterapkan ketika berdagang dengan sikap jujur, nilai akhlak masyarakat Kudus Kulon dan sekitarnya yaitu ramah kepada sesama dan bersikap sopan kepada yang lebih tua, nilai ilmiah yang diterapkan menyekolahkan anaknya ke sekolah yang berbasis pendidikan agama dan umum seperti disekolahkan di TBS, Qudsiyyah, Banat, dll. Nilai spiritual selalu berdagang dengan diselingi mengaji sambil menunggu pembeli dan tidak lupa tetap melaksanakan sholat. Nilai karya yang bisa kita nikmati sekarang seperti karyakarya hasil masyarakat Kudus dan sekitarnya yang dijadikan pajangan dinpusat oleh-oleh toko Gusjigang, sedangkan nilai ekonomi yang dilaksanakan masyarakat Kudus Kulon mayoritas berdagang dan berusaha dengan tetap menjalankan nilainilai filosofi Gusjigang yang telah diajarkan Sunan Kudus pada Zamannya. Nilai filosofi gusjigang berdampak positif bagi kegiatan masyarakat kudus Kulon, di kota Kudus Kulon khususnya desa kerjasan, langgar dalem banyak sekolah Islami maupun Pondok Pesantren yang menerapkan santri dengan menggunakan nilai filosofi gusjigang dalam bermasyarakat dan kehidupannya, dan kini masyarakat dan santri mempunyai akhlak yang baik, sopan santun, dan murah senyum terhadap sesama.

\section{REFERENSI}

Abid, N. (2018). Integrating Soft Skill and Gusjigang Local Value in The Learning Process. ELEMENTARY: Islamic Teacher Journal, 169.

Djoko, S. (2016). Gusjigang dalam Praktik Bisnis. Salatiga: University Press.

Esha, M. I. (2015). NU di Tengah Globalisasi: Kritik, Solusi dan Aksi. 2015: Repository UIN Malang. 
Septy Nadia Salma

Implementasi Nilai Pendidikan Islam melalui Filosofi Gusjigang Bagi Masyarakat

Kudus Kulon

Ihsan, M. (2018). "Gusjigang; Karakter Kemandirian Masyarakat Kudus Menghadapi Industialisasi. Iqtishadia, 153.

Maharromiyati. (2016). Suyahmo. Journal of Educational Social Studies, 163.

Nawali, A. K. (2018). Nilai-nilai Pendidikan Islam dalam Filosofi Hidup 'Gusjigang' Sunan Kudus dan Implikasinya Terhadap Kehidupan Masyarakat di Desa Kauman Kecamatan Kota Kudus. Jurnal Pendidikan Agama Islam , 1-15.

Nur, S. (2013). Gusjigang dan Kesinambungan Budaya Sunan Kudus. Jurnal Penelitian Islam.

Said, N. (2016, Desember Senin). Filosofi Menara Kudus. Pesan Damai Untuk Dunia. Retrieved from eprints: http://eprints.umk.ac.id/4908

59 Print - ISSN: 2443-0021

Online - ISSN: 2716-4136 